\title{
The use of antidepressants and the risk of idiopathic pulmonary arterial hypertension
}

Benjamin D Fox BM BS [1,2,3], Laurent Azoulay PhD [1,4], Sophie Dell'Aniello MSc [1], David Langleben MD [2], Francesco Lapi PharmD PhD [1,5], Jacques Benisty MD [1], Samy Suissa $\mathrm{PhD}[1]$

1. Centre for Clinical Epidemiology, Lady Davis Institute, Jewish General H Canada

2. Center for Pulmonary Vascular Diseases, Division of Cardiold v, Nen Ger heral, Montreal, Canada

3. Department of Medicine, Tel Aviv University, Israel

4. Department of Oncology, McGill University, Montreal Câ da

5. Department of Preclinical and Clinical Pharmacole rryve ity of Florence (Florence, Italy); Agency for Healthcare Services of scar (F en e, Italy)

Running title: Anti-depressants an Pulm hary A rial Hypertension

Word Count: 2496

\section{Correspondence:}

Dr. Samy Suissa

Centre for Clinical

Lady D Is Institute, General Hospital

3755 te-Sainte- $\mathrm{C}$ therine, $\mathrm{H}-461$

Montrea, Quebec anada, H3T 1E2

Tel: 514.340.8zz2; Fax: 514.340.7510

Email: samy.suissa@mcgill.ca 


\section{Abbreviations:}

5HT, 5-hydroxytryptamine (serotonin)

BMI, Body Mass Index

CPRD, Clinical Practice Research Datalink

HES, Hospital Episodes Statistics Database

IPAH, Idiopathic Pulmonary Arterial Hypertension

NSAID, non-steroidal anti-inflammatory drugs

PAH, Pulmonary Arterial Hypertension

SERT, serotonin transporter

SSRI, Selective Serotonin Reuptake Inhibitors

RR, Rate Ratio

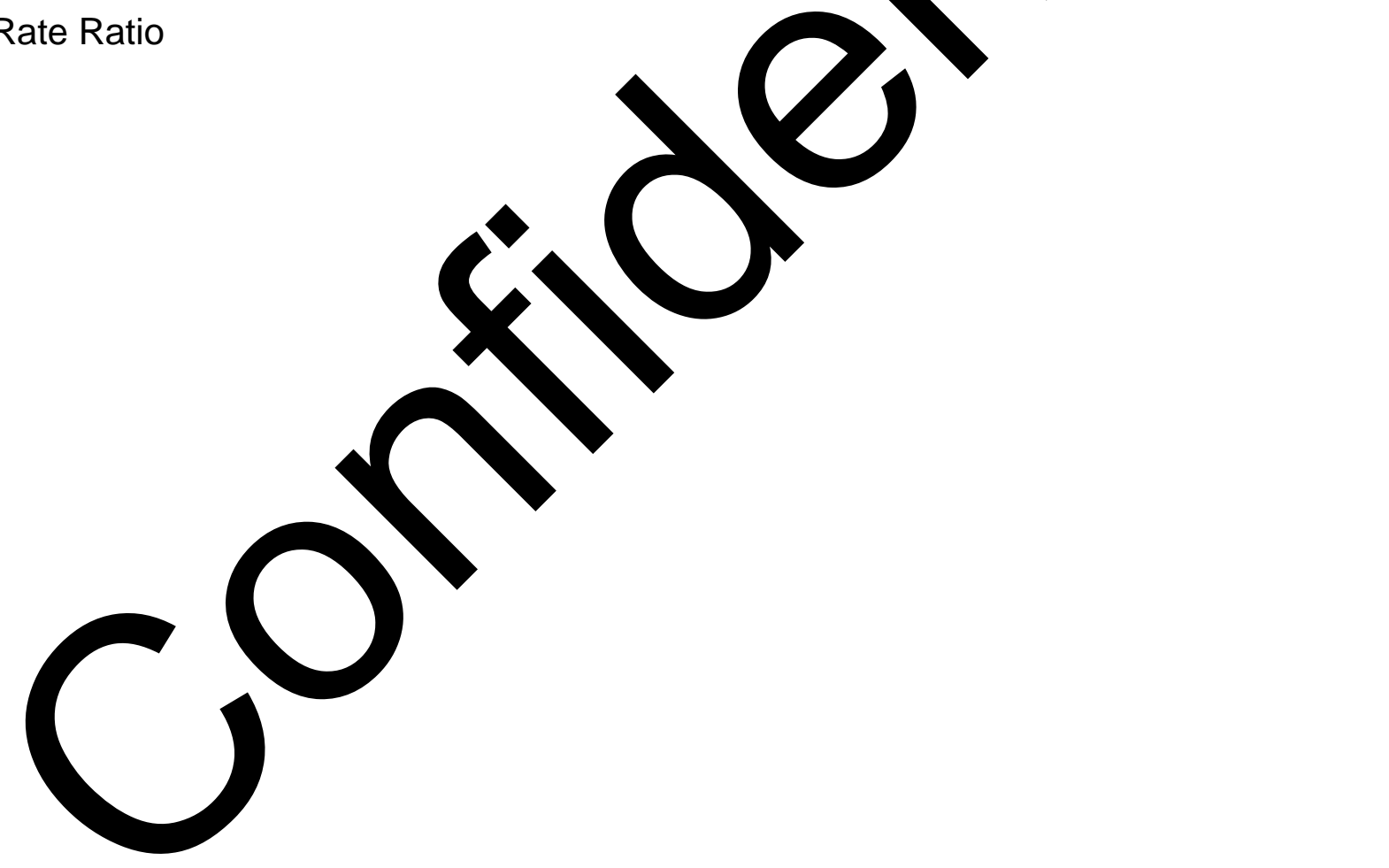




\section{ABSTRACT}

Background: Serotonin has been implicated in the development of idiopathic pulmonary arterial hypertension (IPAH). Drugs modulating serotonin pathways, including antidepressants, have been associated with the incidence of IPAH, with conflicting reports as to the direction of the effect. We aimed to determine whether antidepressant exp ure is associated with the incidence of IPAH.

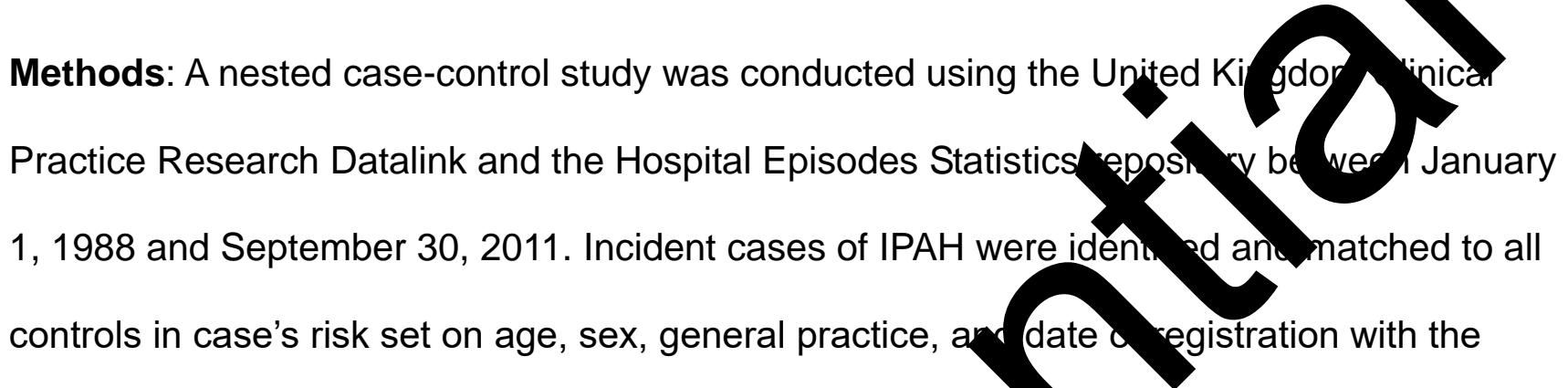
practice. Rate ratios (RRs) and 95\% confidence inte che estimated for the use of antidepressants on the risk of IPAH, with an $-\mathrm{mo}$ ag $\mathrm{p}$ jod prior to the diagnosis. Results: 195 IPAH cases were identified (cideno 3.84/million/year). Use of any antidepressant was associated th 6 inc is of IPAH (RR: $1.67,95 \% \mathrm{Cl}: 1.17-$ 2.37). The rate of IPAH was similar a ss a didepressant classes, whether with Selective Serotonin Reuptake Inhibiton [SST (RR: $1.67,95 \% \mathrm{Cl}: 1.09-2.57$ ) or non-SSRI antidepressants (RB 95 : 1.07-2.59). In sensitivity and exploratory analyses, no change in was bserve with different lag times, serotonin transporter affinities, or duratio s of expose?

Conclus ns: The se of antidepressants was associated with a significantly increased risk of developing IPAH. However, the consistency of this risk across all antidepressants and absence of a dose-response relationship suggests a non-causal association. 


\section{INTRODUCTION}

Pulmonary arterial hypertension (PAH) is a rare but fatal disease of the lung blood vessels.[1] Several anorexigen medications have been strongly associated with the development of $\mathrm{PAH}$, including aminorex, fenfluramine and dexfenfluramine.[1, 2] Anorexigens stimulate serotonin $(5 \mathrm{HT})$ release from the gastrointestinal tract and platelets, increase $5 \mathrm{HT}$ uptake into pulmonary artery smooth muscle cells through the seroto transporter (SERT), and also act as a direct $5 \mathrm{HT}$ agonist at cell surface re
promotes pulmonary artery smooth muscle cell contraction and rolifelon. vitro models of PAH have generally supported this 'serotonin hypoth is' of AH.[3] Inhibition of the SERT molecule is therefore a potential target for pred ention treatment of PAH.

Many antidepressants block SERT, notably th (SSRIs).[4] In a case-control study of patient efer a Imonary hypertension center, use of SSRIs was associated with attrend wards decreased risk of pulmonary hypertension (odds ratio [OR]: 0 (1,95 col wen interval [Cl]: 0.48-1.06) and a decreased risk of death (hazard ratio: $0.35,95 \%$ : 0.10 .88 ).[5] In contrast, in a large case-control study, the use of SSRIs wa assoc with a 55\% increased risk of developing PAH (OR, of 4114 he sub cts, ex psure to SSRIs was associated with a small but measurable increas in right ve ricular mass, consistent with increased right ventricular afterload.[7] Data from the FVEL gistry demonstrated increased likelihood of poor outcomes in PAH patients treated with SSRIs.[8]

In view of the conflicting data surrounding the potential role of antidepressants in the pathogenesis of $\mathrm{PAH}$, we performed a population-based study using the United Kingdom (UK) Clinical Practice Research Datalink (CPRD) and the Hospital Episodes Statistics (HES) 
repository. The objective was to assess whether the use of antidepressants modulating the 5HT pathway are associated with the incidence of developing PAH. The manuscript was drafted with reference to the STROBE guidelines.[9]

\section{METHODS}

\section{Data sources}

This study was carried out using two databases from the UK the Clactice Research Database, and the HEC
as the General Practice largest computerized database of longitudinal records from primary e, co ring more than 12 million people in more than 650 general practices.[10] $\mathrm{CPh}$ is representative of the UK population, both in terms of the geographic distrit general practices and the age and sex distributions of patients.[11] Par ipat practitioners have been trained to record medical information, demagraph data, ody mass index, smoking and alcohol use, medical diagnoses, proced es á de head code classification is used for medical diagnoses and procedures. scrip ons are automatically recorded based on the UK Prescription Pricing Au+t rity D. tionary. CPRD data for diagnoses and medications have been validated.[12,

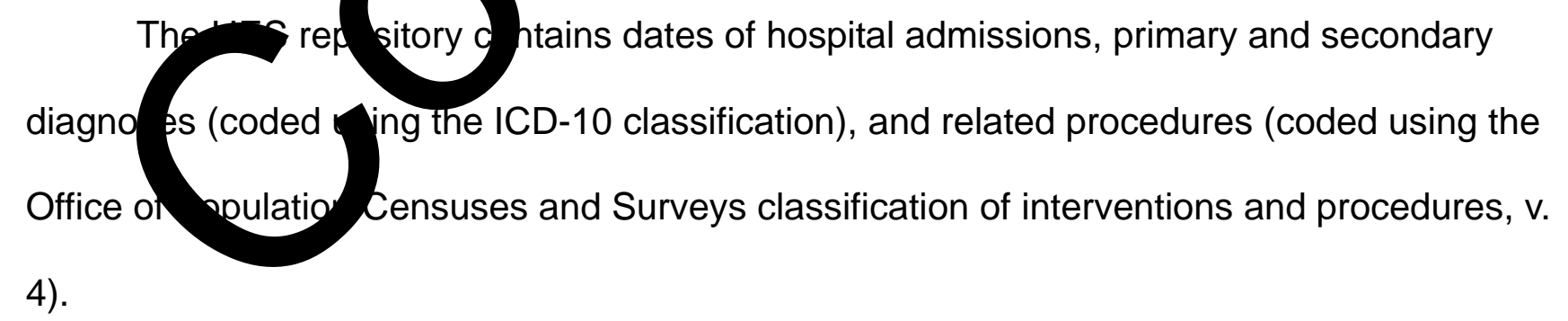

The study protocol was approved by the Independent Scientific Advisory Committee of the CPRD and the Research Ethics Committee of the Jewish General Hospital, Montreal, Canada. 


\section{Study population}

The source population of this study consisted of all patients present in the CPRD between January 1, 1988 and September 30, 2011. Cohort entry was defined as the latest of the following events: January 1,1988 , date of a patient's 12 th birthday, date of current registration, or date of the 'up-to-standard' designation of a patient's general puctice. Patients were excluded if they were not from an up-to-standard practice, had less than one ar of medical history information, were diagnosed with a condition related to ex
or aortic/mitral valvular disease at any time prior to cohort entry. Patien me criteria were followed until a first-ever diagnosis of $\mathrm{PAH}$, diagnosis o, cona ron related to excessive alcohol use or valve disease, death from any cal e, end f registration with the general practice, or end of the study period (Septem 20 , whichever came first.

\section{Case-control selection}

We identified all potential cides cas (Read codes: G41y000, G410.00,70 1300, ,Q01200, 7Q01100, 7Q01000, G42..11, G41z.00, G41..00) or HESar atabas (ICD-10 code 127.0). As a second step, a physician with extensive experience examined the entire computerized medical record of each potential a nd located pe patient to a diagnostic category (idiopathic PAH, PAH associ ed with otk conditions, and no PAH) according to clinical judgment. The physicia vas blin do the patients' age, sex, and antidepressant drug exposure. The computerized medical record included codes for PAH-associated diseases (e.g., connective tissue diseases, congenital heart lesions, portal hypertension, HIV infection), therapeutic procedures associated with $\mathrm{PAH}$ (e.g. right heart catheterization, insertion of hickman catheter), as well as those with diagnoses of cardiac and respiratory diseases associated with 
pulmonary hypertension but not PAH (e.g. pulmonary thromboembolism or sarcoidosis).

Prescriptions for PAH-specific vasodilators (sildenafil, bosentan, ambrisentan, sitaxsentan, epopoprostenol, treprostenil, iloprost), drugs frequently prescribed to patients with PAH (e.g. vitamin $\mathrm{K}$ antagonists, diltiazem, nifedipine, amlodipine) and other cardiovascular or respiratory medications were also included in the reviewed medical records. A seudorandom sample of 200 cases was examined by a second physician (JB) who was ded to the diagnosis of the first physician. The kappa statistic for agreement bety
physicians for the sample was 0.68 representing substantial andeem date was defined as the date of the first-ever diagnosis of IPAH.

All controls were selected from the same CPRD, ES con the Given the rarity of the outcome and to maximize statistical power, we sele ols in the case's risk set, after matching on age ( \pm 5 years), sex, general plyce, cury ht registration date in the practice ( \pm 1 year). By definition, all contro were vive, never diagnosed with IPAH at the

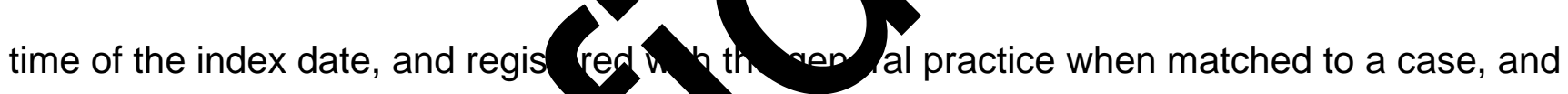
thus had equal duration of medical hr pry in rmation at the index date.

\section{Exposure assessm}

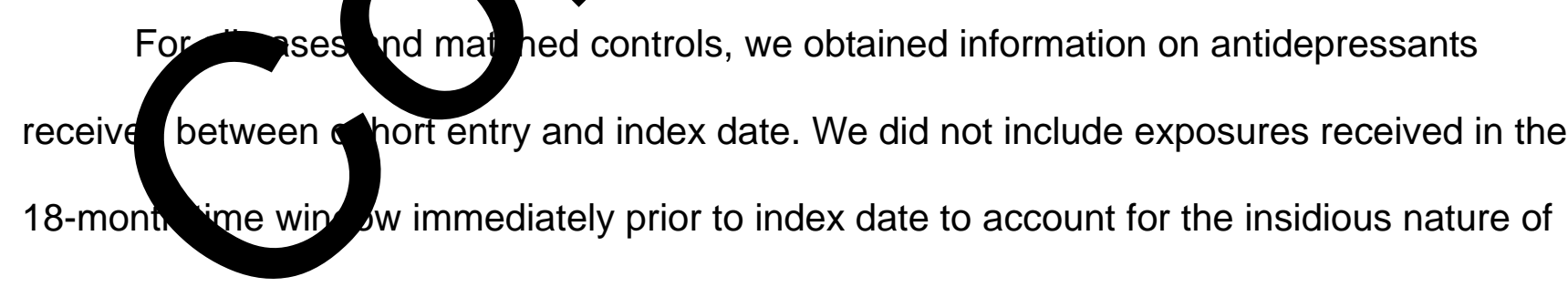

$\mathrm{PAH}$, which results in a lag between onset of symptoms and clinical diagnosis, and to minimize protopathic bias (i.e. depressive symptoms related to IPAH onset leading to antidepressant prescription before the PAH is diagnosed).[16] All classes of antidepressants were considered: tricyclics, SSRIs, monoamine-oxidase inhibitors, other monoamine reuptake 
inhibitors and other miscellaneous classes. Given the uncertainties related to the length of the lag period, we conducted sensitivity analyses varying the lag period to $0,12,24,36,48$ and 60 months.

In secondary analyses, exposure to antidepressant was categorized into three different ways. In the first two, we assessed whether different drug affinity $\left(\mathrm{K}_{\mathrm{D}}\right)$ for botkerotonin and noradrenaline transporters were associated with the incidence of IPAH.[4] For the $\mathrm{rd}$ analysis, we assessed whether cumulative duration of use of antidepress th y ssoulated with the incidence of IPAH. Cumulative duration was calculated sum ing ad trations of all antidepressant prescriptions received between cohort entry and li px da.

\section{Statistical analysis}

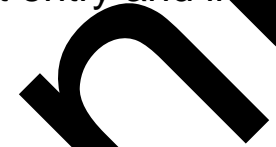

We conducted a nested case-control alys as d this approach because of the time varying nature of the exposure, the si of the cort, and the long duration of followup.[17] This technique is compu ionat efhent hile producing ORs that are estimators of incidence rate ratios ( $)$ wit vittle or no loss in precision.[17, 18, 19] Descriptive statistica ere do summarize the characteristics of the cases and matched controls. W based on oiss distrib tion. Conditional logistic regression was used to estimate the RRs w $195 \% \mathrm{Cls}$ incldent IPAH associated with the use of antidepressants. In additio $7 g e$, se general practice, and year of current registration or 'up-to-standard' designation in the general practice on which the logistic regression models were conditioned, we adjusted for the following potential confounders measured between cohort entry and 18 months before index date: obesity $\left(\mathrm{BMl}>30 \mathrm{~kg} / \mathrm{m}^{2}\right)$, smoking (ever versus never), and in the year prior to the lagged period, the use of antihypertensives, anti-parkinsonian drugs, 
antipsychotics, inhaled corticosteroids, non-steroidal anti-inflammatory drugs (NSAIDs), oral corticosteroids, and narcotic analgesics. All statistical tests were two-tailed.

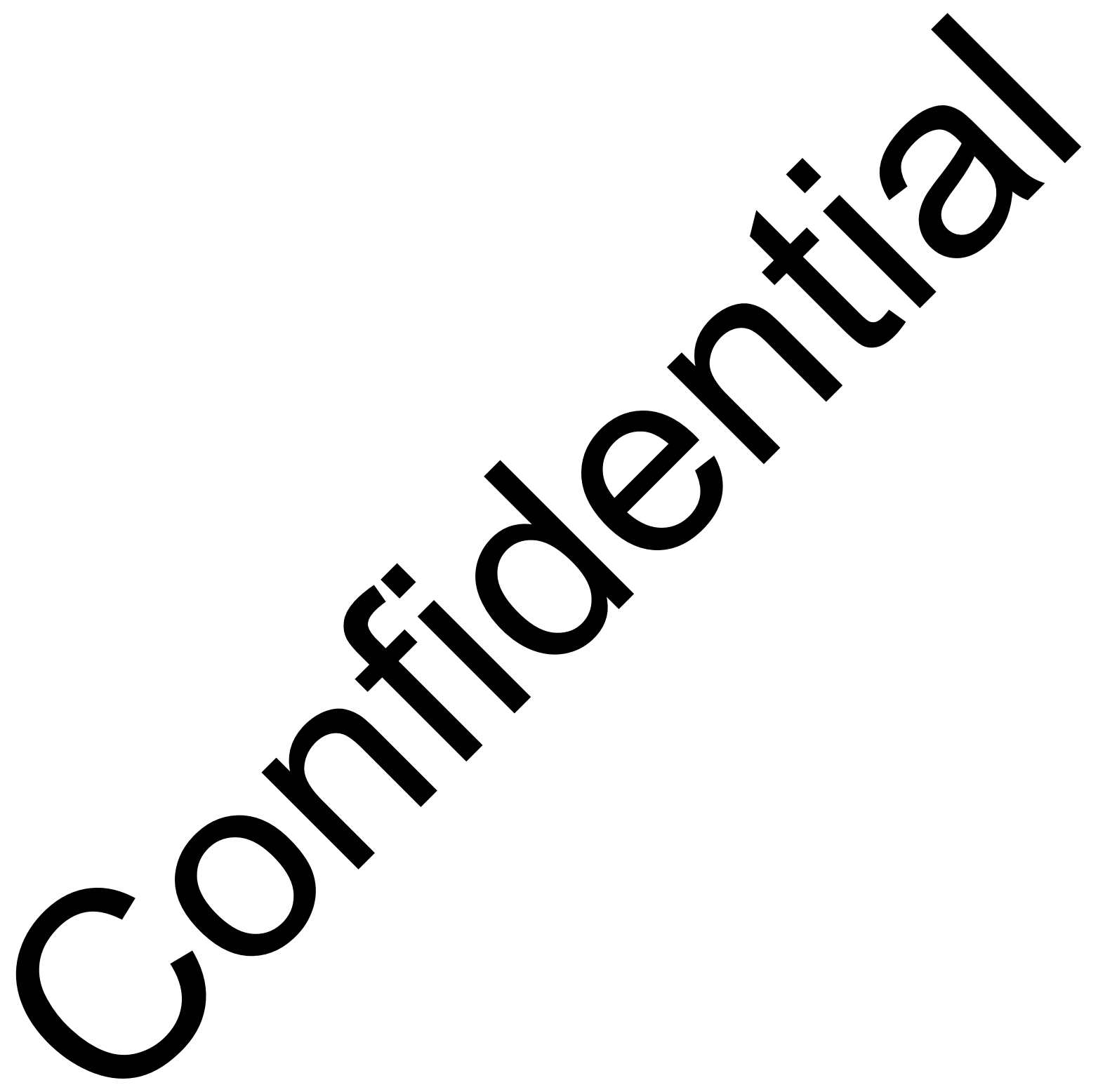




\section{RESULTS}

Overall, a total of 9644 patients with a diagnostic code consistent with $\mathrm{PAH}$ were identified. After initially excluding patients with a PAH diagnosis outside of the study period, pediatric cases, prevalent PAH or patients diagnosed with alcohol-related disorders or valve disease prior to PAH diagnosis, there remained 3192 potential PAH cases (Fiqure 1). After excluding cases with a history of cardiac or pulmonary disease, and $\mathrm{PAH}$-associato conditions, the final IPAH cases consisted of 195 patients, generating an 3.84 (95\% Cl: 3.34 - 4.42) per million per year.

Table 1 presents the characteristics of the cases and matched ontro. The mean age at index date for both cases and controls was 61.6 years andaro eviation: 16.5) and 67\% were females. Compared to controls, cases were mo been obese, and to have used inhaled corticosteroids and antihy, rten $s(\mathrm{Tag}$ le 1$)$.

Table 2 presents the results of the $p$ nary alysis based on an 18-month lag before

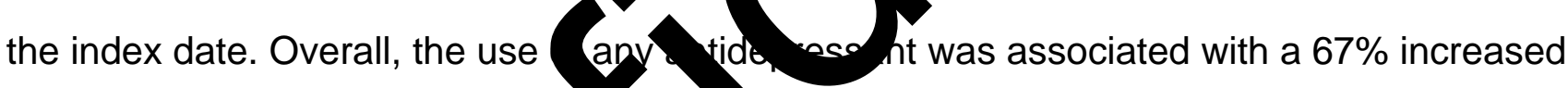
risk of IPAH (RR: $1.67,95 \% \mathrm{Cl}: 1.17$ 37) able 2). The rate of IPAH was similar between SSRIs (RR: 1.67, 95\% CI 9-2.5 and non-SSRI antidepressants (RR: 1.66, 95\% Cl 1.072.59). In the sensitivit which varied the lag period before the index date (Table 3 and Figure 2) sk o develor ig IPAH remained relatively consistent (Figure 2). ble 4 pres th the results of the secondary analyses. Overall, antidepressants categor as hig and intermediate-low affinity for the serotonin or noradrenaline transporter yielded similar RRs for IPAH. Furthermore, there was no effect of cumulative duration of antidepressant use on the risk of IPAH. 


\section{DISCUSSION}

The results of this population-based study indicate that the use of antidepressants was associated with an increased risk of IPAH. However, the association was not specific to the antidepressant class, potency, or by cumulative duration of use. Such consistent results suggest a non-causal association between the use of antidepressants and the sk of IPAH.

To date, the few studies investigating the association between the use of antidepressants and the incidence of PAH have produced conflicting resul this study was based on a case series of patients referred to a aciali center and as such may have been biased.[5] Subsequently, a case-cer rol sth. of PAH patients from Ontario, Canada showed an increased risk of PAH in posed to SSRIs, but not with non-SSRI antidepressants.[6] However, both th stug s, the use of antidepressants was measured at any time prior to the date of the rent, including the period immediately before the event during when th disea phas already begun. Depressive symptoms are prevalent in $\mathrm{PAH}$ patients, raising e colvern of protopathic bias, where the initiation of a drug may have been influen ed by intral signs or symptoms of the outcome of interest (i.e. IPAH) rather th dr itself.[16, 19, 20, 21] Indeed, we believe that the risk of IPAH ass $\mathrm{d}$ inhale corticosteroid use in our study is most likely a protopathic bias reflecti $y$ empirical eatment of dyspnea with asthma medications. If the use of antidepr ants w truly associated with an increased risk of $\mathrm{PAH}$, it would have been expected that the risk would increase with longer lag periods, since exposure would precede the initiation of the first symptoms. In our study, varying the lag period was not associated with a substantial change in the point estimates. Moreover, it would have been expected that exposure to higher potency inhibitors of the SERT or longer cumulative exposure would 
confer a higher IPAH risk. The absence of these effects in our study likely points to a noncausal association between antidepressants and the incidence of IPAH, suggesting that patients with depressive symptoms may be at increased risk of IPAH, independently from their exposure to antidepressants. Indeed, it may be that depression and IPAH share a common genetic dysregulation in 5HT signalling predisposing to both conditions.[23]

This study also has some limitations. Case ascertainment was difficult due the manner in which IPAH was recorded in the database. It is possible that so
missed if they were never recorded in either the CPRD or HES incidence rate of 3.84/million per year is concordant with what has b $n$ pre ously reported elsewhere.[ $24,25,26]$ The relatively high rates of obesityi our co prt are also consistent with prior reports.[27] Our cohort had slightly higher a a than has been previously reported, although no at of cases were slightly older and would therefore be more likely to reguire s th me cations.[24] The rarity of IPAH combined

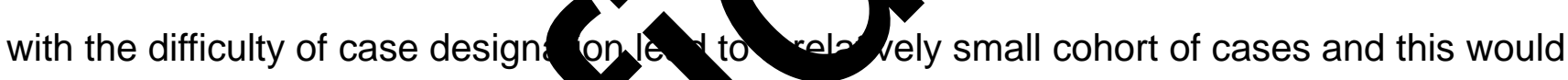
tend to bias our results towards the "-hyphesis. The CPRD uses outdated nomenclature (PPH - primary pulmonary perte (ion) which was superseded the Evian consensus conference in 1998 ont term idiopathic pulmonary arterial hypertension. In addition, nes of the $\eta$ ances of pulmonary hypertension diagnosis amongst nonspecia ts is likely be low such that coding any patient with any form of pulmonary hyperten os as 'P may seem reasonable. In the present cohort only 3.3\% of patients coded by their general practitioner as having PPH were judged by to have IPAH by a PAH specialist. Another limitation in the case ascertainment was that the CPRD/HES do not capture prescriptions written by hospital physicians, which may have increased the likelihood of rejecting a true case. We believe therefore that our case diagnosis was specific but not 
necessarily sensitive. We did not have patient-level physiological data to confirm each case, which is a limitation common to many studies with this type of design.[6,28] A sample of cases was reviewed by a second physician whose classification of patients was in substantial agreement with the first. It should also be emphasized that our cohort was an idiopathic $\mathrm{PAH}$ population, where all secondary or associated causes of pulme ary hypertension had been excluded. The previous studies included either all patients pulmonary hypertension of any cause (including cardiac and pulmonary di
patients with PAH without exclusion of associated diseases.[5, therefore be considered the most accurate to date.

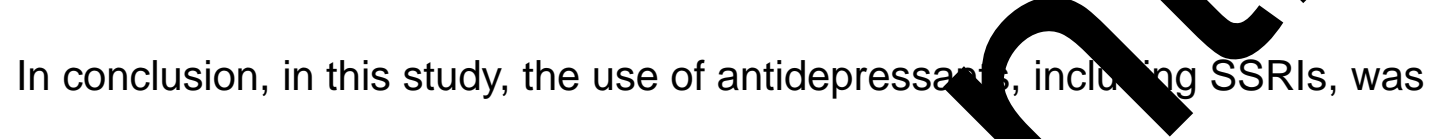
associated with an increased risk of IPAH. However of a differential association between the different types of antidepressan and amy tive duration suggest a noncausal association, and that perhap the in Icatio of use of these drugs may itself be associated with an increased ris of $\mathrm{d}$,

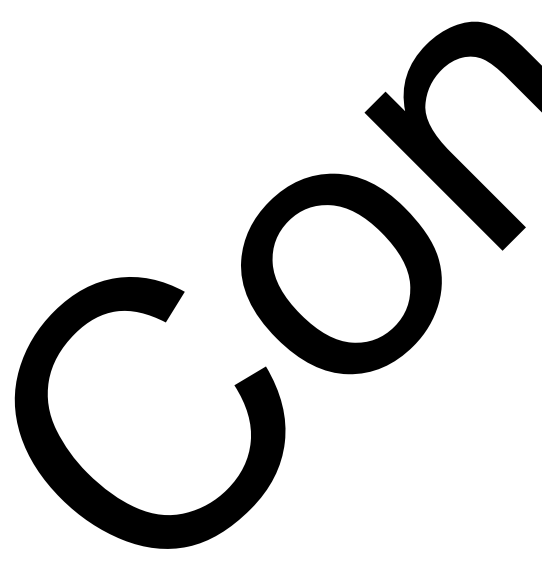




\section{Acknowledgements}

We acknowledge Diane Gaudreau for her administrative assistance.

\section{Funding}

This study was funded by the Canadian Institutes of Health Research. Dr Samy Suissa is the recipient of the James McGill Chair. The funding sources had no role in the dests analysis, and interpretation of the results, and thus the authors were independent from the fur ing source.

\section{Conflicts of Interest:}

None of the authors have a conflict of interest with the cont tho his armele.

\section{Author Contributions}

BDF conceived and designed the study, an yze nanmer preted the data, drafted the manuscript and gave final appro at for ublion. LA designed the study, analyzed interp ted the data, drafted the manscript and gave final approval for publication SD'A designed the studvana zed and interpreted the data, drafted the manuscript and gave final approval for p flication DL des ned the study, mewed the manuscript for important intellectual content and gave final apk val for py jication.

FL interpretea tne data, reviewed the manuscript for important intellectual content and gave final approval for publication.

JB designed the study, analyzed and interpreted the data, reviewed the manuscript for important intellectual content and gave final approval for publication. 
SS designed the study, interpreted the data, reviewed the manuscript for important intellectual content and gave final approval for publication. SS is the guarantor of the manuscript.

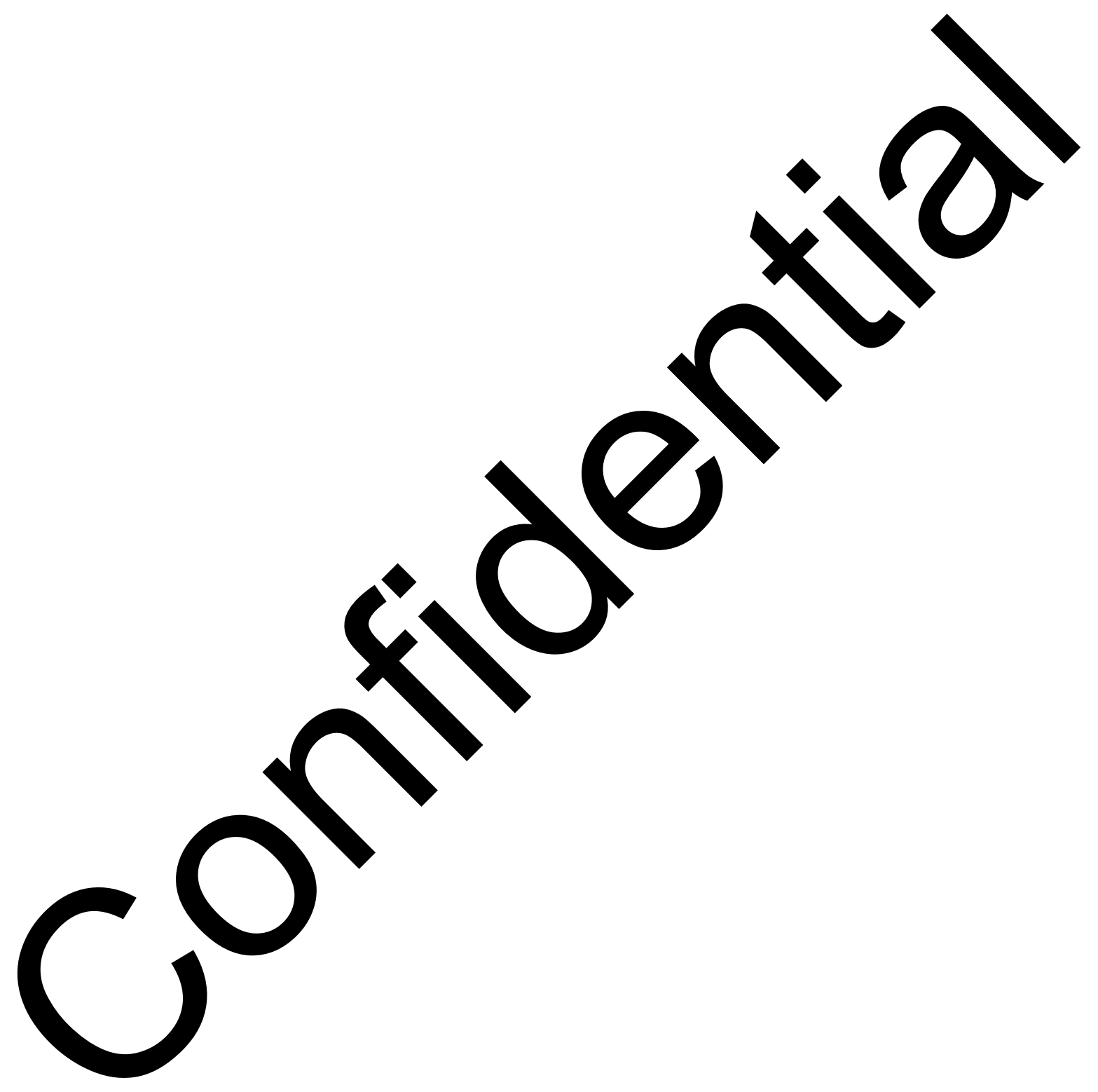




\section{References}

[1] McLaughlin VV, Archer SL, Badesch DB, et al. ACCF/AHA 2009 expert consensus document on pulmonary hypertension: a report of the American College of Cardiology Foundation Task Force on Expert Consensus Documents and the American Heart Association: developed in collaboration with the American College of Che Physicians, American Thoracic Society, Inc., and the Pulmonary Hypertension Association Circulation 2009;119:2250-2294.

[2] Abenhaim L, Moride Y, Brenot F, et al. Appetite-suppressan trugs d th ris of primary pulmonary hypertension. International Primary Pulmonary Hype. nsion, Study Group. $N$ Engl J Med 1996;335:609-616.

[3] Adnot S. The Serotonin System as a Theraputic Yuan JXJ, Garcia JGN, West JB et al, Ê Te ok of Pulmonary Vascular Disease.

[4] Tatsumi M, Groshan K, Blak R R Pich profile of antidepressants and related con, unds, human monoamine transporters. Eur $J$ Pharmacol 1997;340:24-258.

[5] Shah SJ, Gomb inhibit and th incide ce and outcome of pulmonary hypertension. Chest

[6] Dha VA, Juu Ik DN, Gomes T, Granton JT, Zheng H, Mamdani MM. Selective serotonin reuptake inhibitors and pulmonary arterial hypertension: a case-control study. Chest 2012;141:348-353.

[7] Ventetuolo CE, Barr RG, Bluemke DA, et al. Selective serotonin reuptake inhibitor use is associated with right ventricular structure and function: the MESA-right ventricle study. 
PLoS One 2012;7:e30480.

[8] Sadoughi A, Roberts KE, Preston IR, Lai GP, McCollister DH, Farber HW, Hill NS. Use of selective serotonin reuptake inhibitors and outcomes in pulmonary arterial hypertension. Chest. 2013;144:531-41.

[9] von Elm E, Altman DG, Egger M, Pocock SJ, Gøtzsche PC, Vandenbrouch JP; STROBE Initiative. Strengthening the Reporting of Observational Studies in Epidemiolog (STROBE)statement: guidelines for reporting observational stunfies. [10] Walley T, Mantgani A. The UK General Practice Research 1997;350:1097-1099.

[11] Rodríguez LAG, Gutthann SP. Use of the UK Generalf actice search Database for pharmacoepidemiology. Br J Clin Pharmacol 19

[12] Jick SS, Kaye JA, Vasilakis-Scaramozza et alidi of the general practice research database. Pharmacotherapy 2003;23: 6-68

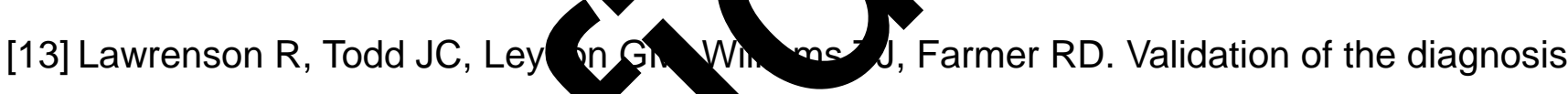
of venous thromboembolism in g eral, actice database studies. Br J Clin Pharmacol 2000;49:591-596.

[14] Lawrenson R, W: practir taba es. J P plic Health Med 1999;21:299-304.

[15] La dis JR, Ko GG. The measurement of observer agreement for categorical data. Bion trics. $19, ; 33: 159-74$.

[16] Horwitz RI, Feinstein AR. The problem of "protopathic bias" in case-control studies. Am J Med. 1980;68:255-58.

[17] Suissa S. Novel Approaches to Pharmacoepidemiology Study Design and Statistical Analysis. In: Strom BL, ed. Pharmacoepidemiology. Chichester, UK:Wiley, 2007:811-29. 
[18] Essebag V, Platt RW, Abrahamowicz M, Pilote L. Comparison of nested case-control and survival analysis methodologies for analysis of time-dependent exposure. BMC Med Res Methodol 2005;5:5.

[19] Essebag V, Genest J, Suissa S, Pilote L. The nested case-control study in cardiology. Am Heart J 2003;146:581-590.

[20] McCollister DH, Beutz M, McLaughlin V, et al. Depressive symptoms in pulmo ry arterial hypertension: prevalence and association with functional status $P$ syd 2010;51:339-339.e8.

[21] Looper KJ, Pierre A, Dunkley DM, Sigal JJ, Langleben D. Depre ive S, Aptoms in relation to physical functioning in pulmonary hyperten n. J chosom Res 2009;66:221-225.

[22] Löwe B, Gräfe K, Ufer C, et al. Anxiety a def son patients with pulmonary hypertension. Psychosom Med 2004;6 831- 6.

[23] Cao H, Gu H, Qiu W, et al. A soriá n S dved serotonin transporter gene polymorphisms and ventricular s tal da cts related possible pulmonary arterial hypertension in Chineas poput ion. Elin Exp Hypertens 2009;31:605-614.

[24] Ling Y, Johnson Gu, et al. Changing demographics, epidemiology, and survival of inciraln nary al prial hypertension: results from the pulmonary hypertension res stry of the ited Kingdom and Ireland. Am J Respir Crit Care Med 2012;186:790796

[25] Escribano-Subias P, Blanco I, López-Meseguer M, et al. Survival in pulmonary hypertension in Spain: insights from the Spanish registry. Eur Respir J 2012;40:596-603. [26] Humbert M, Sitbon O, Chaouat A, et al. Pulmonary arterial hypertension in France: results from a national registry. Am J Respir Crit Care Med 2006;173:1023-1030. 
[27] Burger CD, Foreman AJ, Miller DP, Safford RE, McGoon MD, Badesch DB. Comparison of body habitus in patients with pulmonary arterial hypertension enrolled in the Registry to Evaluate Early and Long-term PAH Disease Management with normative values from the National Health and Nutrition Examination Survey. Mayo Clin Proc 2011;86:105-112.

[28] Suissa S, Patenaude V, Lapi F, Ernst P. Inhaled corticosteroids in COPD and the risk of serious pneumonia. Thorax. 2013;68:1029-36.

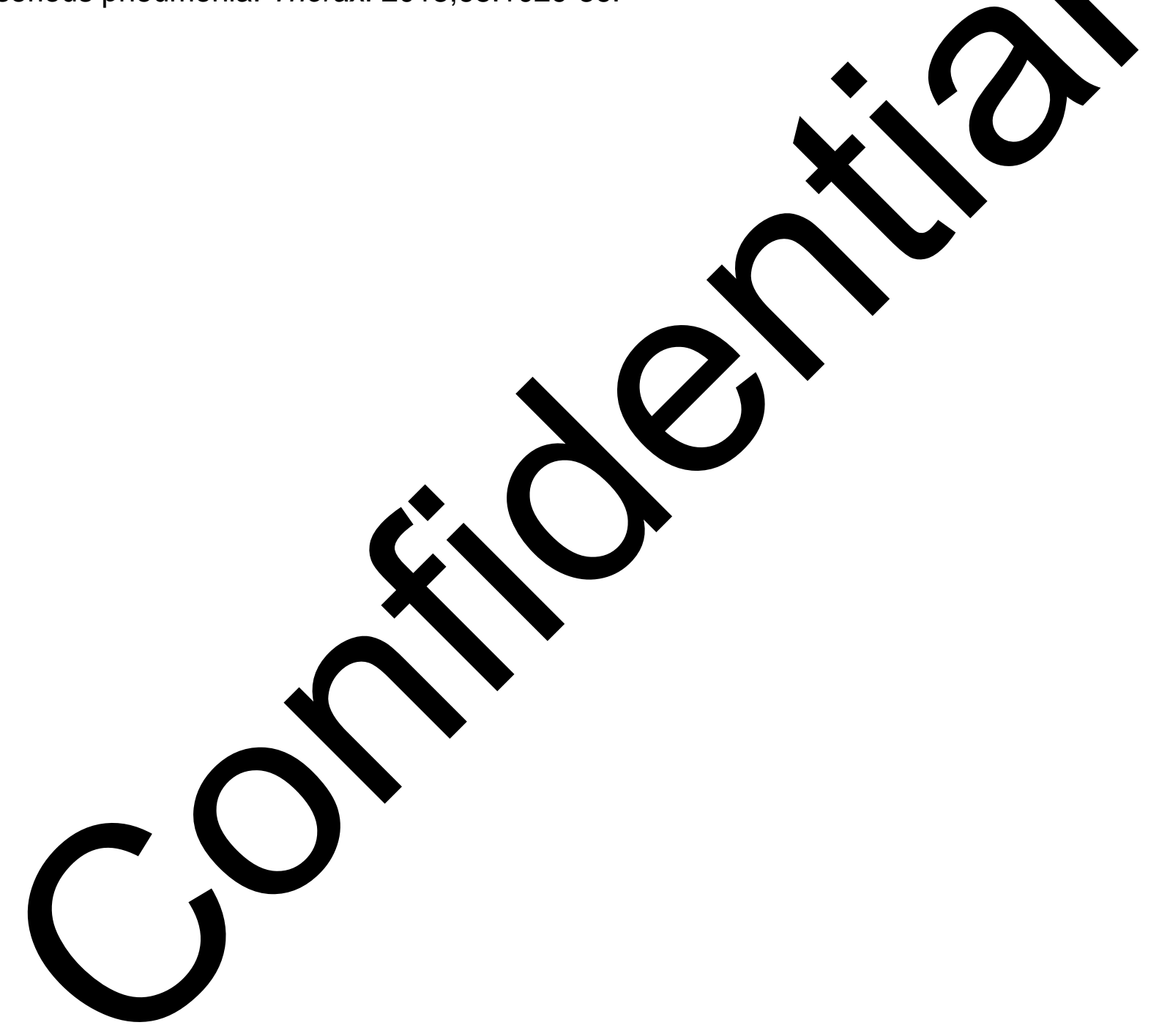


Figure legends:

Figure 1: Case Identification Flowchart.

Figure 2: Risk of developing Idiopathic Pulmonary Arterial Hypertension, at different lag times between exposure to anti-depressants and disease diagnosis. Size of the point estimate is proportional to sample size.

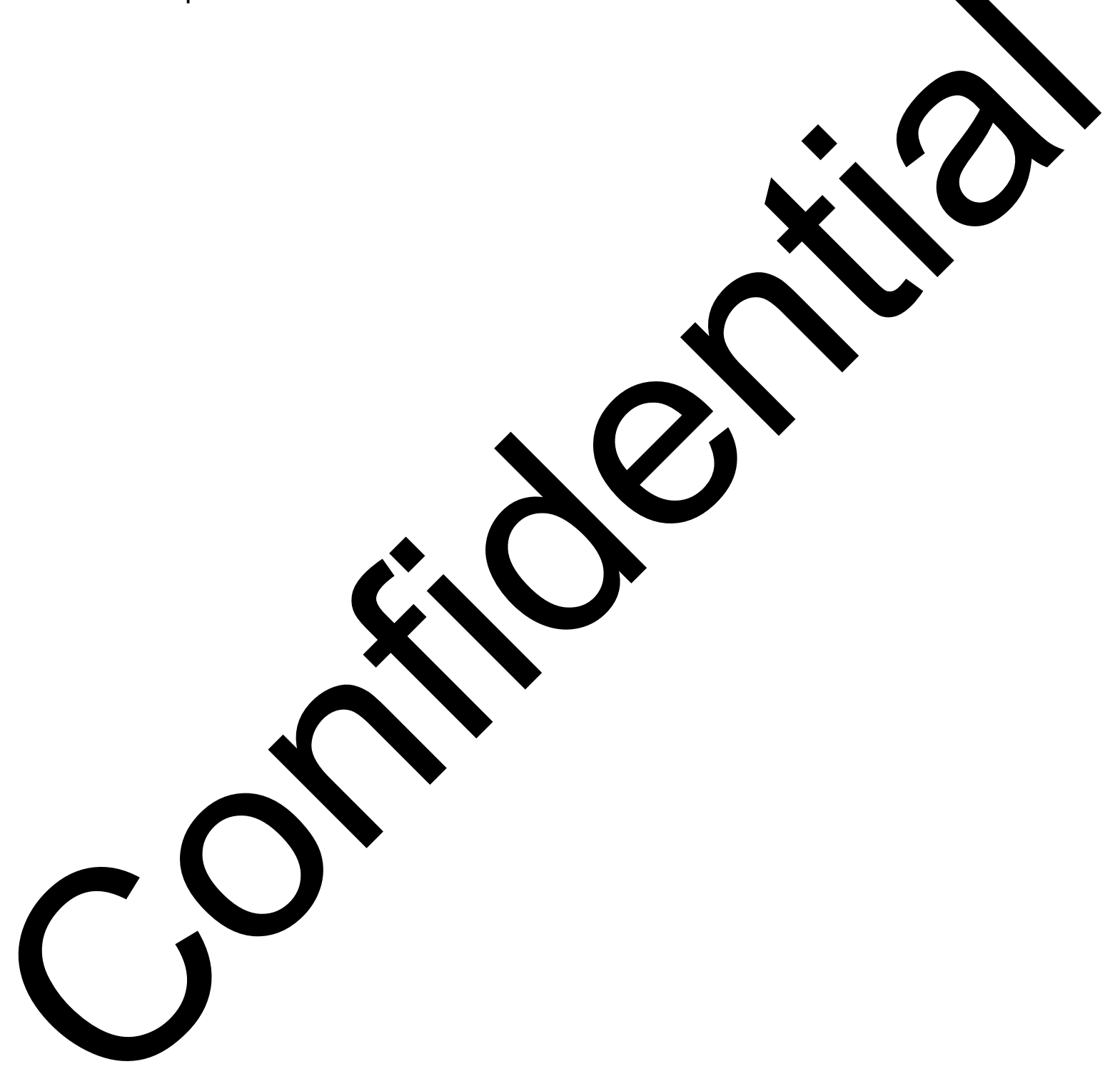


Table 1: Characteristics of cases and matched controls

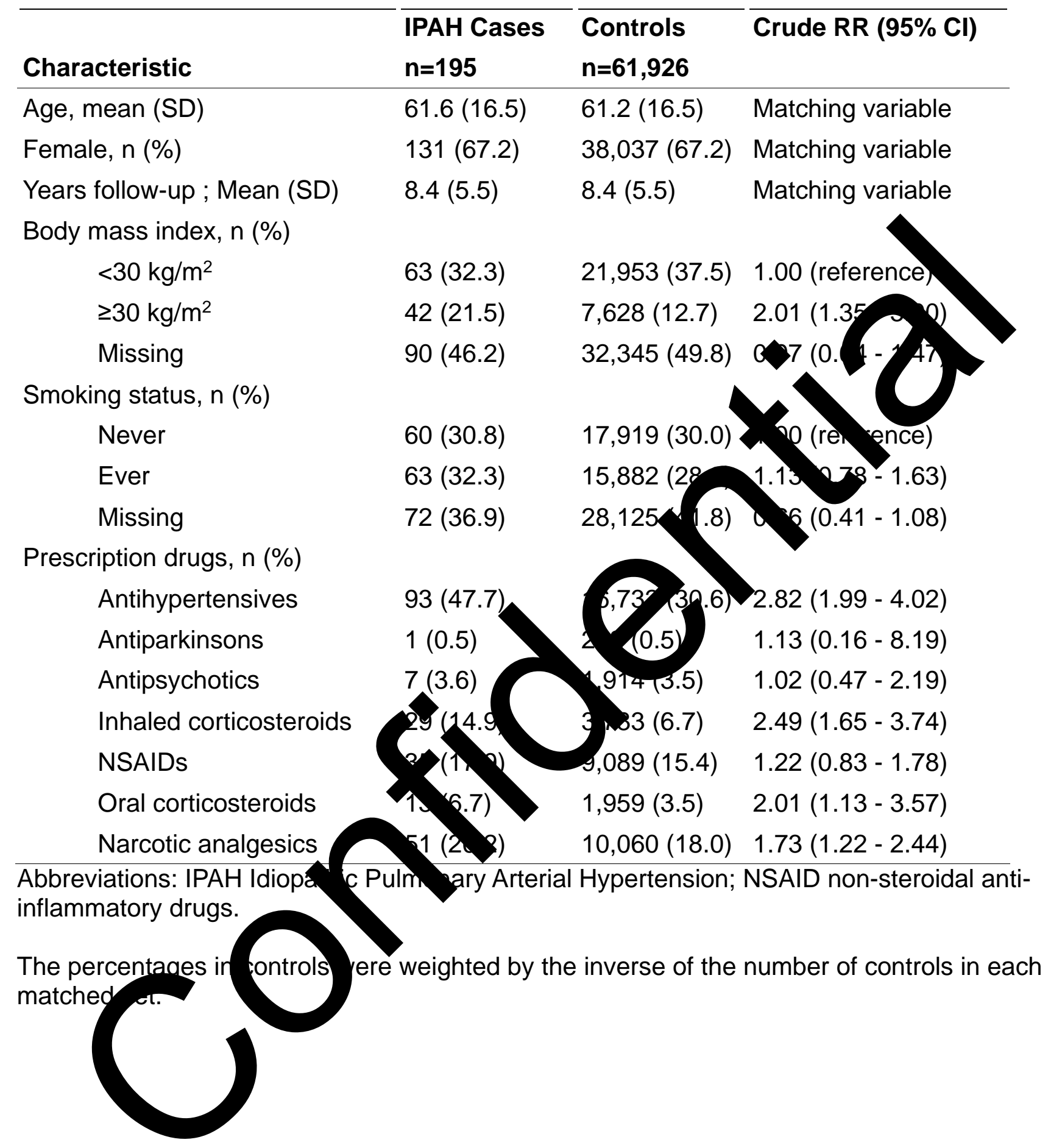


Table 2: Crude odds ratios and adjusted rate ratios of IPAH associated with the use of antidepressants

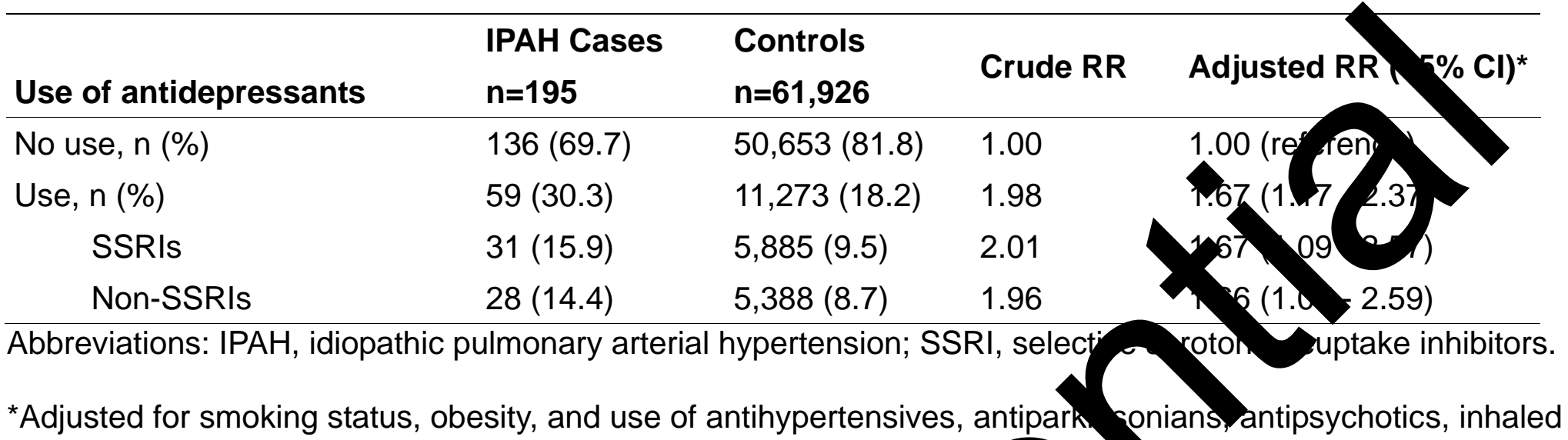
corticosteroids, NSAIDs, oral corticosteroids, and narcotic analgesics

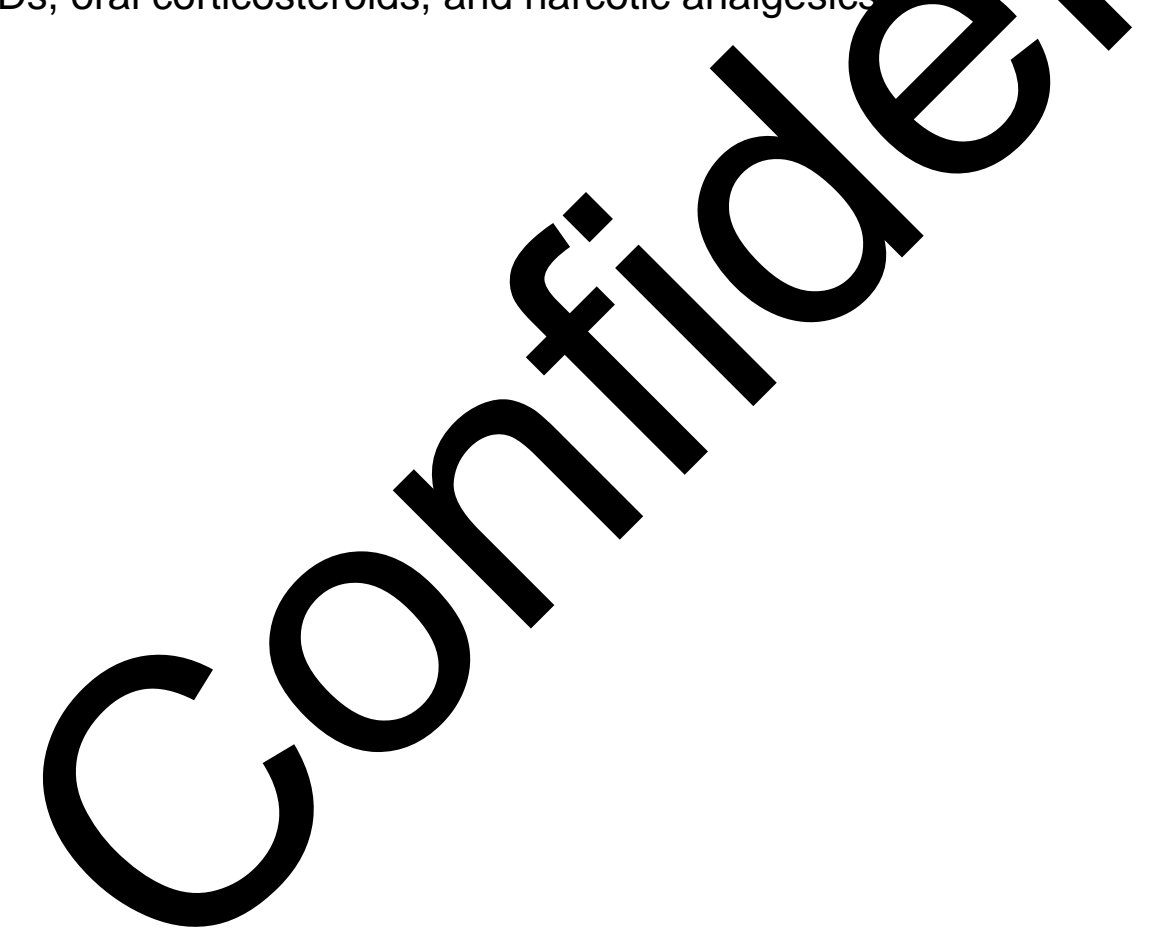


Table 3: Sensitivity Analyses - varying lag times from 0 to 60 months.

\begin{tabular}{|c|c|c|c|c|}
\hline Use of antidepressants & $\begin{array}{l}\text { IPAH Cases } \\
n=195\end{array}$ & $\begin{array}{l}\text { Controls } \\
n=61,926\end{array}$ & Crude RR & Adjusted RR (95\% Cl) \\
\hline \multicolumn{5}{|l|}{ No lag } \\
\hline No use, n (\%) & $123(63.1)$ & $48,223(77.9)$ & 1.00 & 1.00 (Reference) \\
\hline Use, n (\%) & $72(36.9)$ & $13,703(22.1)$ & 2.07 & $1.56(1.12-2.16)$ \\
\hline \multicolumn{5}{|l|}{ 12-month Lag } \\
\hline No use, n (\%) & $134(68.7)$ & $49,937(80.6)$ & 1.00 & \\
\hline Use, n (\%) & $61(31.3)$ & $11,989(19.4)$ & 1.90 & 5) \\
\hline \multicolumn{5}{|l|}{ 24-month lag } \\
\hline No use, n (\%) & $141(72.3)$ & $51442(83.1)$ & & 1.00 (Reference) \\
\hline Use, n (\%) & $4(27.7)$ & $10484(16.9)$ & & $1.62(1.13-2.32)$ \\
\hline \multicolumn{5}{|l|}{ 36-month lag } \\
\hline No use & $148(75.9)$ & & & 1.00 (Reference) \\
\hline Ever use & & & 1.96 & $1.62(1.10-2.38)$ \\
\hline \multicolumn{5}{|l|}{ 48-month lag } \\
\hline No use & & $54137(87.4)$ & 1.00 & 1.00 (Reference) \\
\hline Ever use & & 7789 (12.6) & 1.74 & $1.41(0.93-2.14)$ \\
\hline \multicolumn{5}{|l|}{ 60-month lag } \\
\hline Ever y & $31(15.9)$ & $6553(10.6)$ & 1.73 & $1.43(0.91-2.25)$ \\
\hline
\end{tabular}


Table 4: Effect of drug receptor affinities and cumulative duration of antidepressant use on the incidence of IPAH

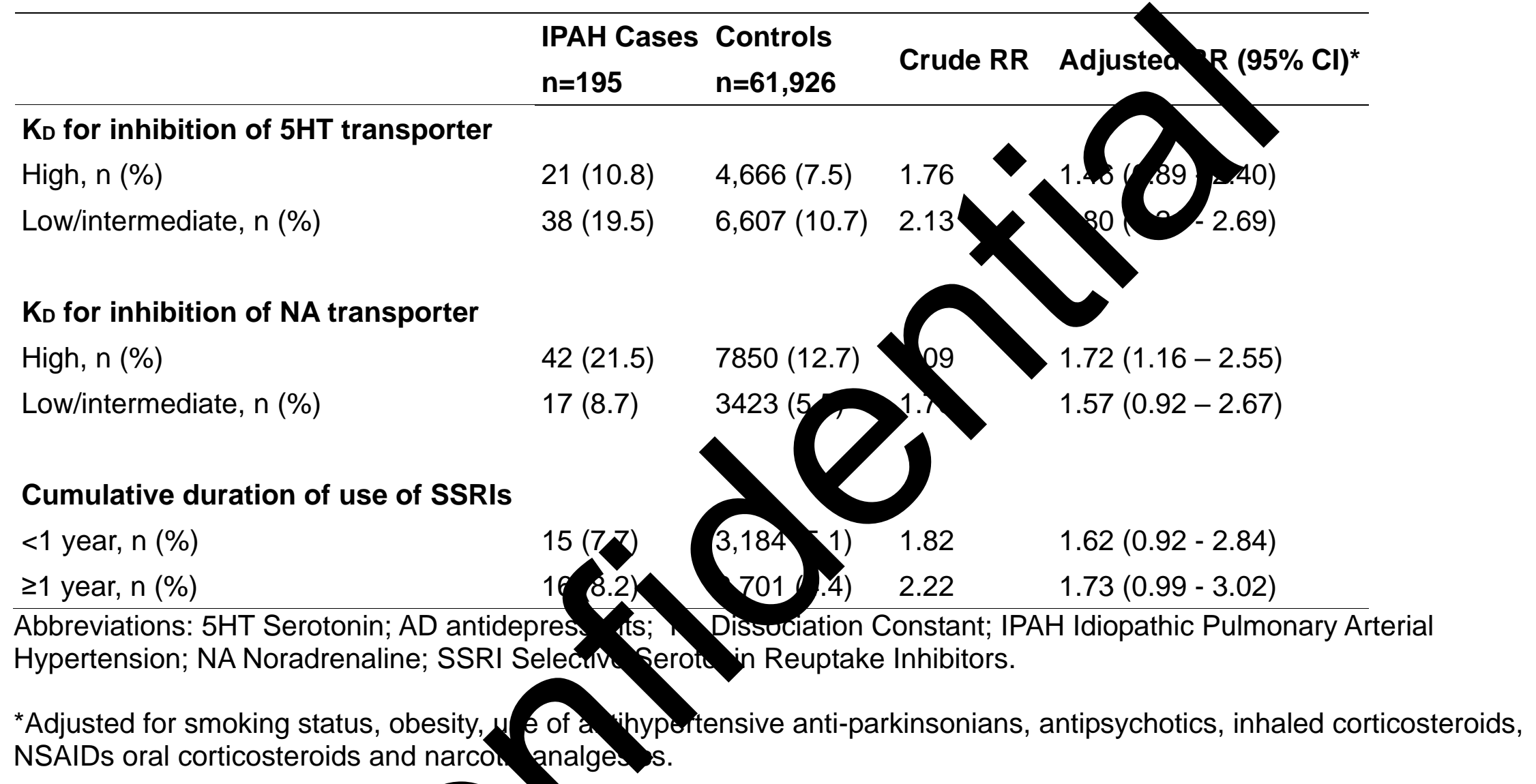


Figure 1

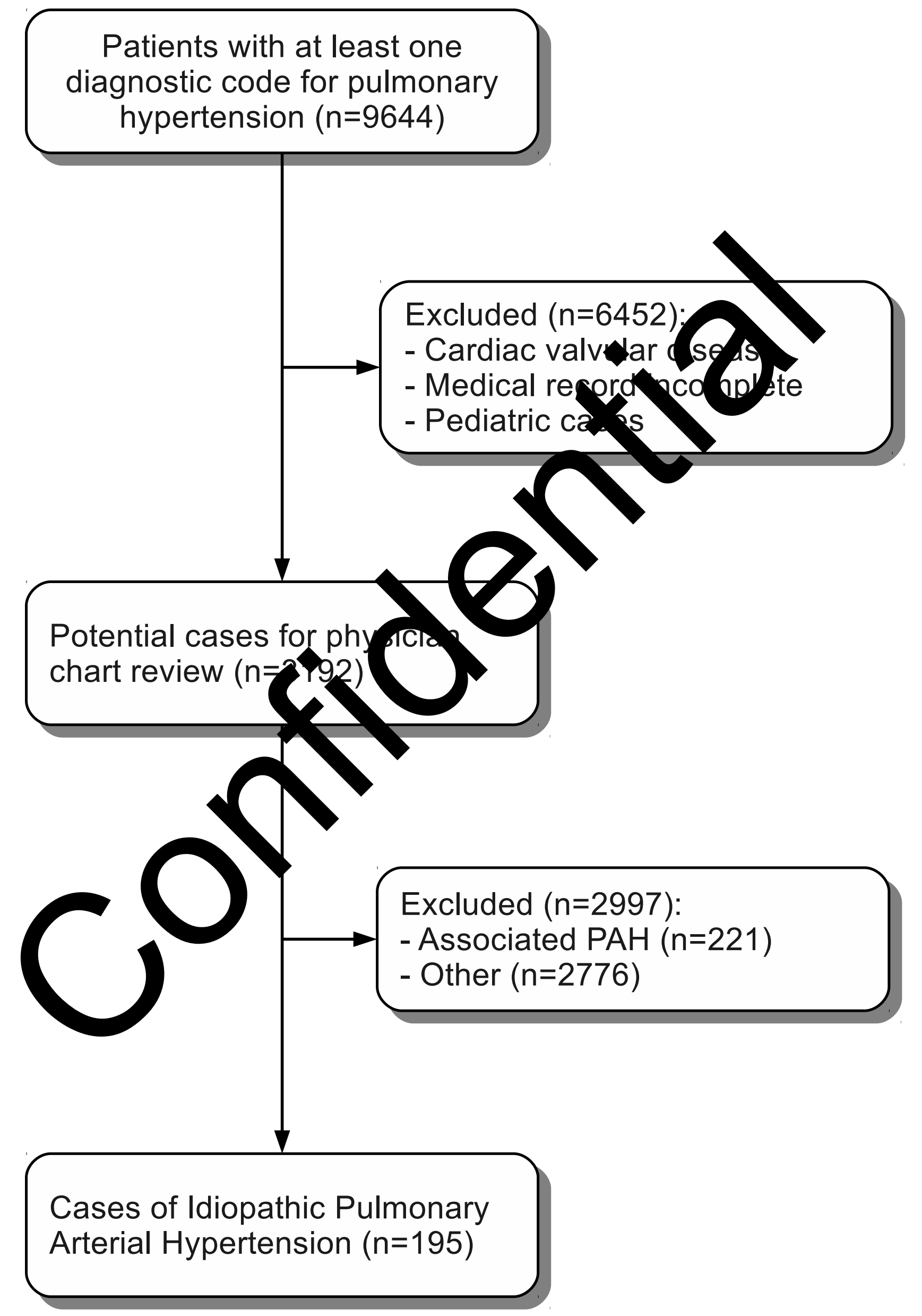




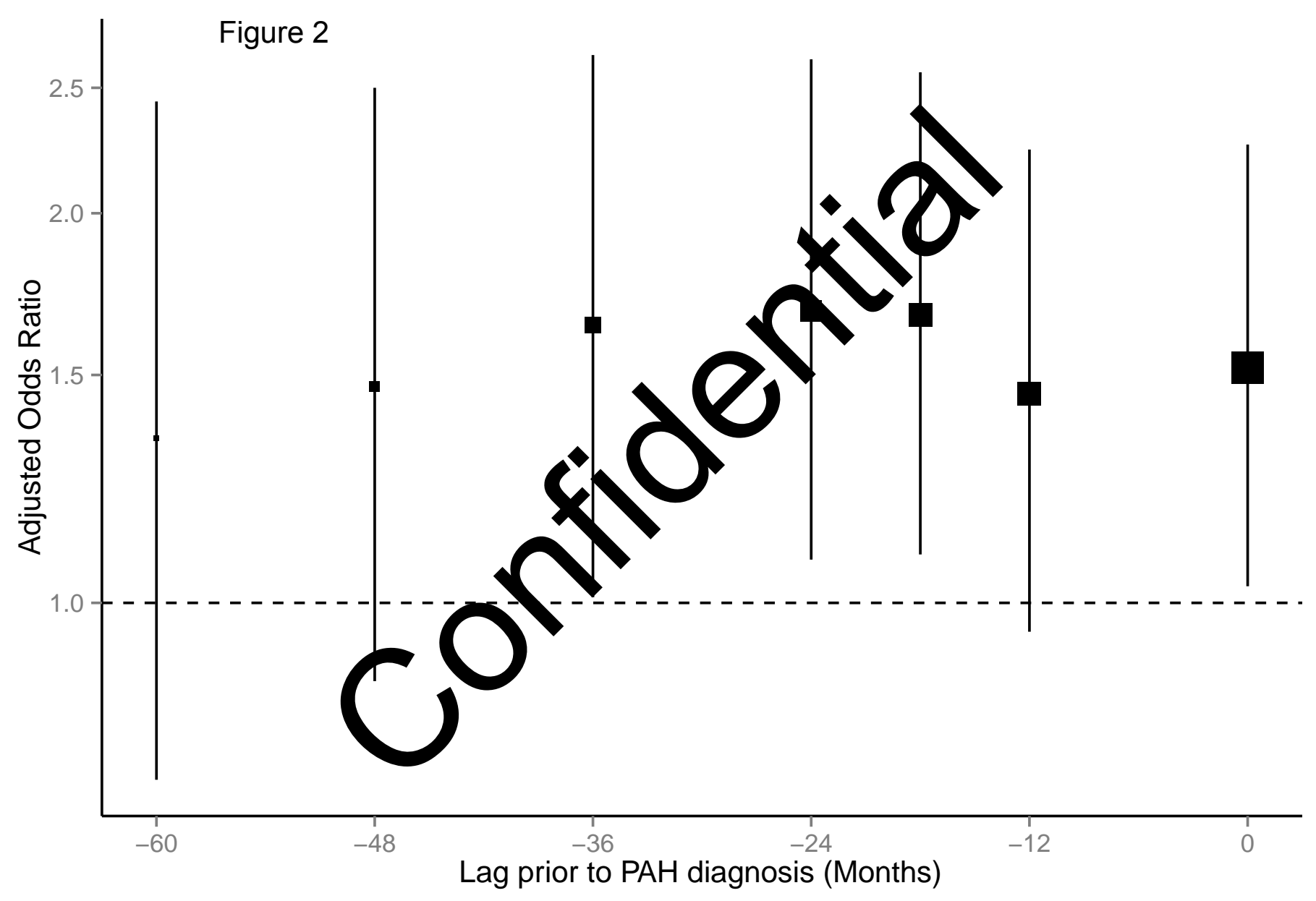

